\title{
Influenza Virus Preservation and its Effect on Infectivity and Viral Load by Lyophilization Technique
}

\author{
Bimalesh Kumar Jha ${ }^{1 *}$, Rajan lav ${ }^{2}$ and Krishna Das Manandhar \\ ${ }^{1}$ National Public Health Laboratory, Teku, Kathmandu, Nepal \\ ${ }^{2}$ Department of Biotechnology, Tribhuvan University, Nepal \\ *Corresponding author: Bimalesh Kumar Jha, National Public Health Laboratory, Teku, Kathmandu, Nepal
}

\section{ARTICLE INFO}

Received: 幽 February 26, 2020

Published: 蔧 March 05, 2020

Citation: Bimalesh Kumar J, Rajan l, Krishna Das M. Influenza Virus Preservation and its Effect on Infectivity and Viral Load by Lyophilization Technique. Biomed J Sci \& Tech Res 26(2)-2020. BJSTR. MS.ID.004330.

\section{ABSTRACT}

Background: Freeze drying (Lyophilization) performed at temperature and pressure below the triple point is being practiced for the preservation of virus stocks for longer periods. The present study is aimed to lyophilize influenza virus strain to study its effects on infectivity and viral load.

Material \& Methods: In-house Influenza virus reference strain (stock virus) was propagated in MDCK cell line in $25 \mathrm{~cm} 2$ cell culture flasks. In 24-well plates the serial dilutions of stock virus from 10-1 to 10-7 (100 $\mu$ linoculum) was inoculated in each well with MDCK cells for TCID50 titer and viral RNA was extracted separately to determine viral load by Real Time PCR. Stock virus was lyophilized in 3 lots and stored at RT $\left(25 \pm 2^{\circ} \mathrm{C}\right.$ ) and $4^{\circ} \mathrm{C}$ separately for 1,4 and 6 months and subjected to TCID50 (for viral infectivity) and viral load assay (for total viral genome copies).

Results: Following lyophilisation and storage of Influenza virus strains at RT and $4^{\circ} \mathrm{C}$ separately did not affect significantly on the viral stability, infectivity as well as viral copy number till 4 months. However, storage at RT for 6 months resulted in 1 log reduction in viral copy number.

Conclusion: Thus, storage of even lyophilized virus stock would necessitate a temperature of at least $4^{\circ} \mathrm{C}$ for prolonged periods.

Keywords: Influenza; Lyophilization; Revival; Viral Load; TCID50

\section{Introduction}

The structure and function of organisms change and get lost with time, as in laboratory cultures. Attempts to stop the biological clock have been conjured by ancient and modern minds; and the heart of many such schemes has been experiments with temperature and water content. Whereas refrigeration technology provides a means of slowing the rate of deterioration of perishable goods, the use of much lower temperatures has proved a means of storing living organisms in a state of suspended animation for extended periods. Influenza virus infectivity is relatively unstable, and titers drop rapidly and unpredictably onstorage under different conditions. Stability can be improved by simple desiccation or drying bysublimation in vacuum [1-9,11-13]. However, the most satisfactory method of storage has been in ampoules at $-60^{\circ} \mathrm{C}$ $[6,7,10,14]$, although Greif (4) reported that the titers of purified suspensions of influenza virus in physiological saline stored at $-65^{\circ} \mathrm{C}$ for 180 days declined significantly. Since freezers capable of maintaining this low temperature are not available in many laboratories, a method of storing influenza virus at higher freezer temperatures or at refrigerator temperature would offer many advantages. Greif $(1,2)$ reported quantitative data showing that it is possible to freeze-dry influenza virus and still retain significant infectivity. Influenza is a highly contagious viral respiratory infection caused by influenza virus whose epidemic and pandemic has resulted in significant mortality and morbidity. It has been reported that annual epidemic of influenza result in an estimated 3 - 5 million cases of severe illness and about $290000-650000$ deaths globally. To preserve maximum infectivity for long periods, cell culture-grown adenovirus must be stored frozen at very low 
temperatures [15]. However, this makes its handling difficult. The removal of water from viable biological material in the frozen state (freeze-drying) provides another means of arresting the biological clock by withholding water and commencing again by its addition. Lyophilization or freeze-drying is a controllable method of dehydrating labile products by vacuum desiccation [16]. It is considered advantageous to freeze dry viruses and vaccines wherever possible in order to reduce their volume for storage in cold, to enable easy handling and transport, and to enhance their keeping quality [17]. We have studied the feasibility of lyophilizing large numbers of ampoules of several different strains of influenza virus to maintain infectivity for prolonged periods of storage at refrigerator temperature for use as reference reagents.

\section{Methods and Methodology}

\section{Cell Line and Virus Stock Preparation}

A confluent monolayer (90\%) of the MDCK cell lines were grown in $25 \mathrm{~mm}^{2}$ presterile disposable NUNC tissue culture flask using Minimum Essential Media (MEM) with antibiotics (penicillin, streptomycin) and 10\% fetal calf serum (FCS). Influenza virus reference strain isolated from Department of National Influenza Centre, National Public Health Laboratory, Teku was propagated for virus stock preparation in MDCK cell line and used for TCID50 assay and viral load.

\section{Virus Titration by Tissue Culture Infectious Dose $\mathbf{5 0}$ (TCID50) Assay}

MDCK cell monolayer was prepared and virus infection was performed at different dilutions in $10 \mathrm{ml}$ sterile tissue culture tubes. Cell monolayer was observed daily till the cytopathic effect (CPE) appeared, along with the control wells (MEM inoculated) kept under the same condition. TCID50 titer was be calculated by using Reed and Muench [18].

\section{Extraction of Viral RNA}

Viral RNA was be extracted from $140 \mu$ of tissue culture lysate using RNeasy Minikit (QIAGEN, GmbH, Hilden, Germany) according to the manufacturer's instructions.

\section{Lyophilization of Stock Virus}

The virus was lyophilized or freeze dried in 3 batches of 6 vials Each using TFD5503 benchtop lyophilizer using the instrument protocol.

\section{Revival of Lyophilized Virus}

Lyophilized virus was revived in sterile conditions using sterile double distilled water after 1,4 and 6 months. The virus ampoule was opened of the ampoule in the bio-safety cabinet. $1 \mathrm{ml}$ sterile water was added to the dried virus and mixed gently. The revived virus was kept at 4 degree $\mathrm{C}$ for (1-2) Hr and aliquated and subjected to TCID50 and real Time PCR for viral load estimation.

\section{Estimation of Viral Load in lyophilized Virus}

To determine the effect of Lyophilization on influenza viral load the lyophilized influenza virus was subjected to real time PCR, the ct values obtained were extrapolated with standard curve to estimate the vial load in samples.

\section{Data Analysis}

The viral titre and load between stock and lyophilized virus were compared by a paired sample ttest. The correlation between viral load and TCID50 was studied using Spearman correlation coefficient. Statistical analysis of significance was undertaken using SPSS 16.0 software with a value of $(\mathrm{P}<0.05)$ for significance.

Ethical Consideration Ethical approval was obtained from National Public Health Laboratory and Nepal Health Research Council (NHRC ref. no. 1673) before carrying out this study.

\section{Results}

\section{Confirmation of Stock Virus}

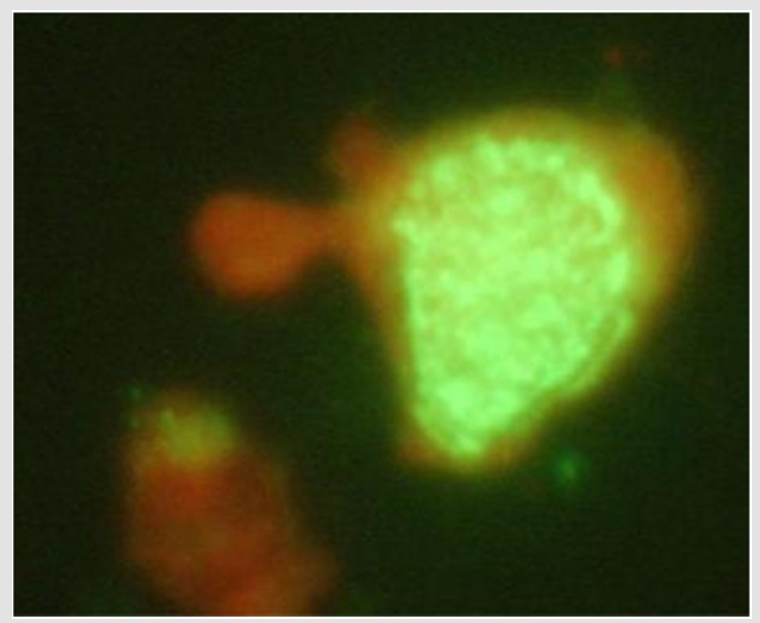

Figure 1: Influenza Virus Infected MDCK Cells Stained with Influenza $\mathrm{Ab}$ and FITC Conjugated Antimouse $\mathrm{Ab}$ Showing Intra Nuclear Green Fluorescence.

Influenza virus reference strain (kindly obtained from National Influenza centre, National Public Health, Laboratory, Teku) was successfully propagated in MDCK cell lines. Cytopathic effect (CPE) positive cell culture flasks for influenza virus infected cells showed cell grapening, clustering, rounding, clumping and focal dislodging of cells in comparison to control mock infected cells (only Media Inoculated) were seen on second to third days post inoculation. CPE positive cells were scrapped with a sterile cell scrapper and subjected to Immunofluorescence using polyclonal antisera for Influenza virus. It showed the characteristic intra nuclear brilliant apple green fluorescence in influenza infected cells Figure 1 . These culture bottles were preserved at $-80^{\circ} \mathrm{C}$ deep freezer and subjected to repeated freeze and thaw in three occasions for cell lysis. The 
supernatant was transferred to a sterile vial and centrifuged aseptically. The clear supernatant containing the virus particles was used as positive control for qualitative RT-PCR as well as preparation of standards in Quantative Real Time RTPCR.

\section{Comparison of TCID50 Titer of Lyophilized Virus Stored for Different Time Intervals}

The lyophilized virus was stored at RT and $4^{\circ} \mathrm{Cfor} 1$ month, 4 months and 6 months. The virus was revived after these fixed intervals of time and infected in MDCK to check the infectivity of virus and change in the TCID50 titer. It was observed that lyophilized virus was infective till 6 months and there was no change in the TCID50 titer of the lyophilized Influenza revived after 1 month to 6 months of storage at $4{ }^{\circ} \mathrm{C}$. In case of lyophilized influenza stored at Room temperature the TCID50 titer was observed to reduce from 10-4.5 at 1 month to $10-3.22$ at 4 months but it remained constant to 10-3.22 after 6 months of storage (Figure 2).

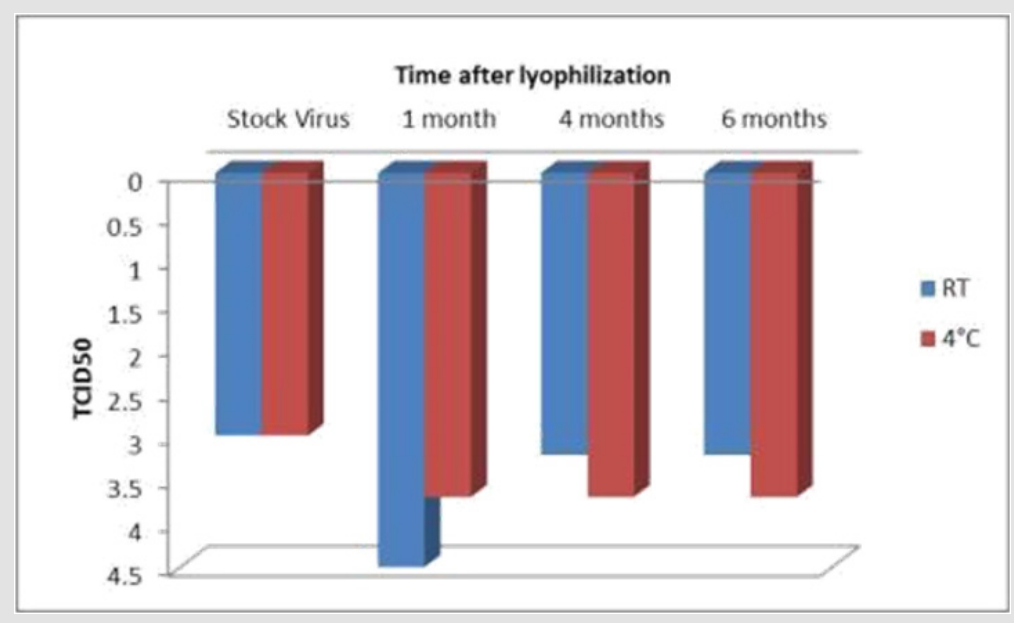

Figure 2: Comparison of TCID50 in Stock Virus and Lyophilized Virus Revived at Different Time Intervals. The Value of TCID50 on Y- axis Corresponds to 10-y of Different Sample of Influenza Virus.

Table 1: Arrangement of data in calculation of TCID50 titer by Reed and Muench formula.

\begin{tabular}{|c|c|c|c|c|c|c|}
\hline \multirow{3}{*}{ Virus dilution } & \multirow{3}{*}{ Infected } & \multirow{3}{*}{$\begin{array}{c}\text { Non- } \\
\text { Infected }\end{array}$} & \multicolumn{4}{|c|}{ Accumulative Values } \\
\hline & & & \multirow{2}{*}{ Infected } & \multirow{2}{*}{$\begin{array}{c}\text { Non- } \\
\text { infected }\end{array}$} & \multicolumn{2}{|c|}{ Mortality } \\
\hline & & & & & Ratio & Percent \\
\hline 1-Oct & 4 & 0 & 14 & 0 & $14 / 14$ & 100 \\
\hline $10-2$ & 4 & 0 & 10 & 0 & $10-0 \mathrm{ct}$ & 100 \\
\hline 3-Oct & 3 & 1 & 6 & 1 & 7-Jun & 85.71 \\
\hline 4-Oct & 2 & 2 & 3 & 3 & 6-Mar & 50 \\
\hline 5-Oct & 1 & 3 & 1 & 6 & 7-Jan & 14.28 \\
\hline 6-Oct & 0 & 4 & 0 & 10 & $0 / 10$ & 0 \\
\hline
\end{tabular}

\section{Comparison of TCID50 Titer of Lyophilized Virus Stored for Different Time Intervals and Stock Virus}

The TCID50 titer of the lyophilized Influenza virus stored at RT and $4^{\circ} \mathrm{C}$ for 1,4 and 6 months was compared with that of the stock virus. The TCID50 titer of lyophilized virus is summarized in Table 1 whereas the TCID50 titer of stock virus was observed to be 10-3. No significant difference was observed in the TCID50 titer or the infectivity of the lyophilized virus stored at $4^{\circ} \mathrm{C}$ for 1,4 and 6 months as well as Influenza stored at RT for 4 and 6 months as compared to the stock virus. The Influenza viral load in stock and lyophilized adenovirus was correlated with TCID50 titer as described in the Table 2 using Spearman correlation coefficient.
However, no statistical correlation was observed in the viral load and TCID50 titer.

Confirmation of successful cloning: Hexon region of the viral genome was cloned in pGEM-T Easy vector and transformed in E. coli DH5 $\alpha$. Cloned plasmid containing the Influenza hexon insert had a defective LacZ gene and those cells are transformed with this vector formed white colony in ampicillin agar plate (Figure 3). White colony from the plate, theoretically containing the desired inserts were picked and subjected to plasmid extraction. The plasmids isolated from the white colonies were subjected to PCR to yield 161bp bands in agarose gel. PCR resulted in $161 \mathrm{bp}$ amplicon with hexon region specific primer pair (Figure 4). 
Table 2: Correlation of TCID50 and Viral load in lyophilized and stock virus.

\begin{tabular}{|c|c|c|c|c|}
\hline \multicolumn{2}{|c|}{ TCID50 } & \multicolumn{2}{c|}{ Viral Load by Real-Time PCR (Copies/ml) } \\
\hline Stock virus & & \multicolumn{2}{|c|}{$\mathbf{1 5 9 0 0 0 0 0}$} \\
\hline $\begin{array}{c}\text { Lyophilized Influenza } \\
\text { revived after 1 month }\end{array}$ & Stored at 4 ${ }^{\circ} \mathbf{C}$ & Stored at RT & Stored at 4 ${ }^{\circ} \mathbf{C}$ & 68100000 \\
\hline $\begin{array}{c}\text { Lyophilized Influenza } \\
\text { revived after 4 months }\end{array}$ & $10-4.5$ & $10-3.7$ & 29200000 & 72000000 \\
\hline $\begin{array}{c}\text { Lyophilized Influenza } \\
\text { revived after 6 months }\end{array}$ & $10-3.22$ & $10-4.5$ & 22200000 & 26500000 \\
\hline
\end{tabular}

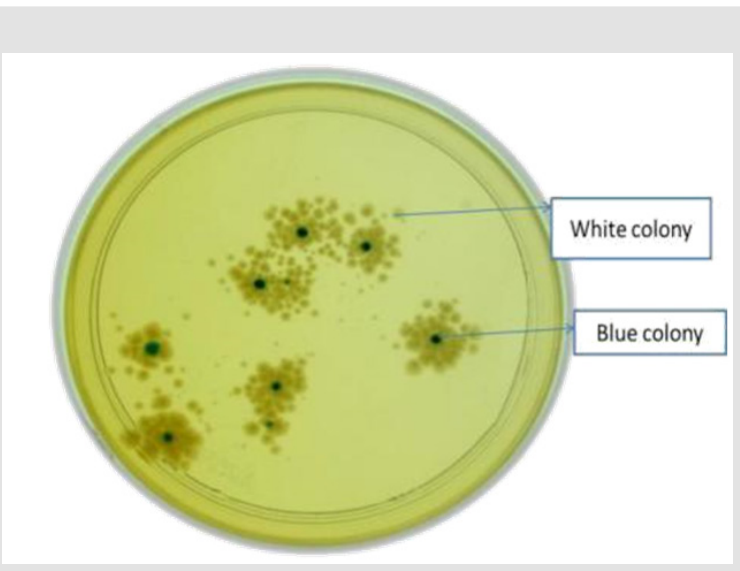

Figure 3: Plate Showing Blue (vectors without inserts) and White (vectors with insert) Colonies.

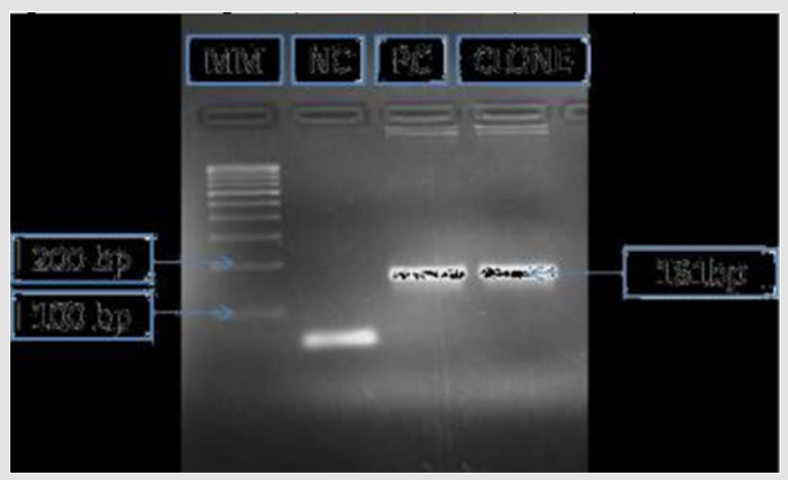

Figure 4: Conformation of Successful Cloning; lane1: 100 Base Pair Molecular Marker (Fermentas, USA), lane 2: NC and 3: PC \& lane 4: 161 bp Band using Hexon Specific Primer in Influenza Clone.

\section{Comparison of Viral Load of Lyophilized Virus Stored for Different Time Intervals}

The effect of lyophilization on viral load of Influenza over a period of time was studied. No significant difference was observed in viral load of $\mathrm{AdV}$ stored at $4^{\circ} \mathrm{C}$ for 1, 4 and 6 months. However, in lyophilized virus stored at RT a significant difference in viral load was observed between the virus stored for 1 month and that stored for 6 months at RT $(\mathrm{P}<0.05)$ but no difference was observed in viral load of Influenza stored at RT for 1 and 4 months (Figure 5).

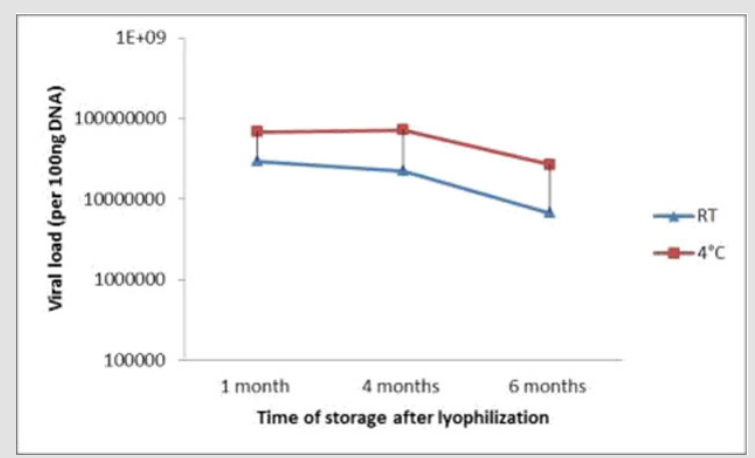

Figure 5: Viral Load of Lyophilized Virus Stored at RT and $4^{\circ} \mathrm{C}$ for 1 to 6 months.

\section{Discussion}

Freeze-drying will not reverse damage incurred prior to formulation and care must be exercised when selecting an appropriate cell type or technique used to culture or purify the cell or its extracts prior to freeze-drying. To sustain freeze-drying it is necessary to establish a pressure gradient from a sample (highest pressure), to condenser, and finally vacuum pump (lowest pressure) so that water migrates from the sample as drying progresses. In the present study Influenza virus was successfully propagated in MDCK Cell line. The lyophilization cycle was standardized and the virus suspension was lyophilized at temperature below $-40^{\circ} \mathrm{C}$ and under $50 \mathrm{~m}$ Torr vacuum. The essence of the formulation exercise should be to minimize freeze-drying damage, loss of viability, or activity. This study considers the stability of Influenza virus after freezedrying and storage and also determines its titer and load. The infectivity of the virus was retained when stored for over 6 months at $+4^{\circ} \mathrm{C}$ or RT. We determined the TCID50 titer of the Influenza virus lyophilized for 1-6 months and observed no significant difference in the infectivity when stored at $+4^{\circ} \mathrm{C}$ or RT.

Thus, the cell culture-grown Influenza virus could withstand the freeze-drying process, and it should be stored at $+4^{\circ} \mathrm{C}$ and RT to retain maximum infectivity. Many culture collections and gene banks insist on high recovery values prior to a protocol being adopted for regular use; $50 \%$ viability post thaw has been 
accepted in some culture collections as a nominal cutoff for adopting maintenance by cryopreservation alone [5]. The ability to determine viral titer rapidly and at high accuracy is one of the most important tools desired when working with viruses in the research laboratory [6,7]. Real-time PCR has been shown to be more sensitive than cell culture-based techniques for detection of viruses in clinical specimens; it was therefore interesting to investigate whether realtime PCR technology could also be an important tool for rapid and efficient estimation of viral titer [8]. In the present study the viral load of stock and lyophilized adenovirus was determined and compared with each other. The viral laod of the lyophilized virus stored at $4^{\circ} \mathrm{C}$ was observed to increase as compared to the stock virus whereas that stored at RT for 1 and 4 months the viral load increased slightly but at 6 months the viral load decreased as compared to the stock virus. There is evidence that a cryopreservation method yielding high initial recovery values, maintains viability at that level on prolonged storage. Titer determined using either by PFU or endpoint dilution (TCID50) assays, methods that are time consuming and labor intense [9].

As a complement to these established methods of determination of virus titers, we here describe a Real-Time Quantitative PCR assay that enables rapid recording of viral load values that corresponds to titer measurements of viruses. However, the results presented here showed no significant relationship between Real Time PCR $\mathrm{v} / \mathrm{s}$ TCID50. Even though the TCID50 technique is time consuming, need expertise but is capable of dealing with the infective/live virus which has the great importance in viral isolation, manufacturing live attenuated vaccines, viral antigen and viral standards. Real Time PCR which detects both the infective and non-infective viral particles is highly sensitive and rapid, used most popularly in the viral diagnostic labs and has great importance in the early diagnosis and management by of the patient [8]. It should, however, be taken into consideration that viruses causing persistent infection that consequently would give a positive signal in real-time PCR cannot be converted to viral titer, as this would give a false impression that the virus is able to cause cytopathic effect. Our data also demonstrated that using real-time PCR technology is a reliable, rapid and robust method that corresponds to standard quantification methods used to measure viral titers. Thus, highly reproducible over a dynamic range of viral concentrations commonly used in research laboratories and could therefore save time in comparison with the traditional cell culture based viral titration methods. The reproducibility of quantitative real-time PCR was higher than for TCID50, which could be partially explained by the fact that realtime PCR does not require a manual estimation based on visual observations.

\section{Conclusion}

The present study could successfully lyophilize Influenza virus and retain its infectivity over a period of 6 months when stored at
RT and $4{ }^{\circ} \mathrm{C}$. No significant difference in the infectivity or TCID50 titer was observed in the lyophilized virus as compared to the stock virus. However, the viral load was observed to increase with Lyophilization of the virus over 6 months when stored at $4{ }^{\circ} \mathrm{C}$ which possibly is due to the concentration of the virus on freeze-drying.

\section{Declarations}

\section{Author Contribution Statement}

a) Bimalesh kumar jha: Conceived and designed the experiments, performed the experiments, wrote paper.

b) Rajan lav: Performed the experiment, analyzed the data.

c) Krishna Das Manandhar: Conceived and designed the experiments; Contributed reagents, materials, analysis tools or data; Wrote the paper

Finding Statement: This research did not receive any specific grant from funding agencies in the public, commercial or non for profit organization.

Competing Interest: The authors declare that they have no competing interests.

Availability of data: All necessary data are included in paper. Remaining data will be provided by corresponding authors on reasonable request.

\section{Acknowledgement}

We express our deep gratitude to all laboratory staffs of National Influenza Centre, National public health laboratory, Teku and Department of biotechnology tribhuvan university, Nepal for their kind support to completing this work. We are also thankful to head of Department who provided us to chance to carry the study.

\section{References}

1. Grelff D (1960) The effects of freezing, low temperature storage and drying of vacuum sublimation on the activities of viruses and cellular particulates. In: A Parkes and A U Smith [Eds.]., Recent research in freezing and drying, Blackwell Scientific Publications, Oxford pp. 167187.

2. Greeff D, H Blumenthal, M Chiga, HPinkerton (1954) The effects on biologic materials of freezing and drying by vacuum sublimation II. Effect on influenza virus. J Exptl Med 100(1): 89-101.

3. Greiff D, WA Rightsel (1965) An accelerated storage test for predicting the stability of suspensions of measles virus dried by sublimation in vacuo. J Immuno 94: 395-400.

4. Greiff D, W Rightel (1966) Freezing and freeze-drying of viruses In: HT Meryman (Eds.)., Cryobiology. Academic Press, Inc, New York, USA. pp. 697-728.

5. Hare R, L Mcclelland, J Morgan (1942) A method for the concentration of influenza virus. Can Public Health J 33: 325-331.

6. Hirst GK (1941) The agglutination of red cells by allantoic fluid of chick embryos infected with influenza virus. Science 94(2427): 22-23.

7. Horsfall FL (1939) Neutralization of epidemic influenza virus: Linear relationship between the quantity of serum and the quantity of virus neutralized. J Exp Med 70(2): 209-222. 
8. Kreuger AP (1942) and the technical staff of U.S. Naval Laboratory Research Unit No. 1 at the University of California at Berkeley. The inactivation of influenza virus by the human skin. Naval Med Bull Wash 40: 839-846.

9. Parker ER, WB Dunham, WJ Macneal (1944) Resistance of the Milbourne strain of influenza virus to dessication. J Lab Clin Med 29: 37-42.

10. Reed LJ, H Muench (1938) A simple method of estimating fifty per cent endpoints. Am J Hyg 27: 493-497.

11. Scherp HW, EW Flosdorf, DR Shaw (1938) Survival of the influenza virus under various conditions. J Immunol 34(6): 447- 454.

12. Shope RE (1931) Swine influenza filtration experiments and etiology. J Exptl Med 54(3): 373-385.

13. Shope RE (1934) The infection of ferrets with swine influenza virus. J Exp Med 60(1): 49-61.

ISSN: 2574-1241

DOI: $10.26717 /$ BJSTR.2020.26.004330

Bimalesh Kumar Jha. Biomed J Sci \& Tech Res

(C) This work is licensed under Creative

Submission Link: https://biomedres.us/submit-manuscript.php
14. Turner TB (1938) Treponema pallidum and Treponema pertenue in the frozen state; with a note on the preservation of filterable viruses. J Exptl Med 67(1): 61-78

15. Croyle MA, Cheng X, Wilson JM (2001) Development of formulations that enhance physical stability of viral vectors for gene therapy. Gene Ther 8(17): 1281-1290.

16. Nail SL, Jiang S, Chongprasert S, Knopp SA (2002) Fundamentals of freeze-drying. Pharm Biotechnol 14: 281-360.

17. Schersch K, Betz O, Garidel P, Muehlau S, Bassarab S, et al. (2010) Systematic investigation of the effect of lyophilizate collapse on pharmaceutically relevant proteins I: stability after freeze-drying. J Pharm Sci 99(5): 2256-2278.

18. Chen S, Guo D, Guo B, Liu J, Shen Y, et al. (2012) Investigation on formulation and preparation of adenovirus encoding human endostatin lyophilized powders. Int J Pharm 427(2): 145-152.

\begin{tabular}{ll} 
BIOMEDICAL & Assets of Publishing with us \\
RESEARCHES & - Global archiving of articles \\
& - Immediate, unrestricted online access \\
\hline IsSN: $2574-1241$ & - Rigorous Peer Review Process \\
\hline
\end{tabular}

